\title{
Prevent Transmission of HIV/Safety Blood Supply
}

National Cancer Institute

\section{Source}

National Cancer Institute. Prevent Transmission of HIVISafety Blood Supply. NCI

Thesaurus. Code C15838.

Develop and assess multiple and concurrent ethical intervention strategies to reduce or prevent HIV transmission in both domestic and international settings. 